\title{
Should We Adopt a Standard International Normalized Ratio Range of 2.0 to 3.0 for Asian Patients with Atrial Fibrillation? An Appeal for Evidence-Based Management, Not Eminence- Based Recommendations
}

\author{
Tze-Fan Chao ${ }^{1,2}$ Yutao Guo ${ }^{30}$ \\ ${ }^{1}$ Division of Cardiology, Department of Medicine, Taipei Veterans \\ General Hospital, Taipei, Taiwan \\ 2 Institute of Clinical Medicine, and Cardiovascular Research Center, \\ National Yang-Ming University, Taipei, Taiwan \\ ${ }^{3}$ Department of Cardiology, Chinese PLA General Hospital, \\ Beijing, China
}

Thromb Haemost 2020;120:366-368.

The prevalence of atrial fibrillation (AF) and AF-related stroke are increased in Asian countries in recent years, ${ }^{1,2}$ and stroke prevention with oral anticoagulants (OACs) is the cornerstone for the managements of $\mathrm{AF}^{3,4}$ Although nonvitamin $\mathrm{K}$ antagonist OACs (NOACs) were more and more commonly prescribed, warfarin was still responsible for around $27 \%$ of prescriptions of OACs for newly diagnosed AF patients in year 2015 in Taiwan. ${ }^{5}$

When using warfarin, we have to think beyond simply writing a prescription for it. Good treatment quality assessed by international normalized ratio (INR) and time in therapeutic range (TTR) is important for warfarin therapy. Some data suggest that the risk of warfarin-related intracranial hemorrhage (ICH) may be different between different ethnic groups. In the subanalysis of ENGAGE AF-TIMI 48 trial, patients of Asian races were associated with a higher adjusted risk of ICH (adjusted hazard ratio: $1.71 ; p=0.03$ ) compared with non-Asians despite a lower INR range. ${ }^{6}$ Actually, whether there should be a lower INR range for Asian AF patients remains as a debate for many years mainly due to the lacking of high-quality data of randomized trials. Indeed, some studies have tried to focus on stroke and bleeding in Asian populations, attempting to define thromboembolic and bleeding issues in this ethnic group. ${ }^{7-9}$ Nevertheless, an "Asian" group is very broad-and South Asians from the Indian subcontinent are very different from oriental subjects from East Asia or Central Asia, whether biologically or culturally.

received

January 13,2020

accepted

January 13, 2020

Address for correspondence Tze-Fan Chao, MD, PhD, Division of Cardiology, Department of Medicine, Taipei Veterans General Hospital, No. 201, Sec. 2, Shih-Pai Road, Taipei, Taiwan (e-mail: eyckeyck@gmail.com).

The recommendations of different Asian guidelines on the optimal INR ranges for AF patients treated with warfarin are summarized in - Table 1. The Taiwan Heart Rhythm Society, China Society of Pacing and Electrophysiology/Chinese Society of Arrhythmia, and Korean Heart Rhythm Society recommend 2 to 3 as an optimal INR range, ${ }^{10-12}$ which was similar to the majority of western guidelines. However, Japanese, Indian, and Chinese Geriatric Society guidelines recommend a lower INR range for elderly patients. ${ }^{13-15}$ The Japan Circulation Society (JCS) recommends an INR range of 1.6 to 2.6 for AF patients aged $\geq 70$ years, ${ }^{13}$ while the Chinese Geriatric Society and Indian consensus guidance suggest an INR level of 2.0 (range $=1.6-2.5$ ) for patients aged $>75$ years. ${ }^{14,15}$ Regarding the quality of warfarin use, the Taiwan Heart Rhythm Society, China Society of Pacing and Electrophysiology/Chinese Society of Arrhythmia, and Korean Heart Rhythm Society recommend a TTR $>65 \%$, while the JCS recommends a TTR above $60 \%$. These discrepancies of recommended INR range between different Asian guidelines reflect the uncertainty regarding this important issue, given the lack of high-quality studies.

In this issue of Thrombosis and Haemostasis, Pandey et al present a meta-analysis of 79 randomized controlled trials, where lower INR targets were associated with increased thromboembolism, decreased major bleeding, and similar mortality compared with standard INR ranges. ${ }^{16}$ In a subgroup analysis of only East Asian trials, lower INR target ranges were associated with higher rates of thromboembolism. The authors concluded that an INR range of 2 to 3 should remain the

(c) 2020 Georg Thieme Verlag KG Stuttgart · New York
DOI https://doi.org/ 10.1055/s-0040-1702230. ISSN 0340-6245. 
Table 1 Summary of the recommendations on international normalized ratio range for stroke prevention in nonvalvular atrial fibrillation in different Asian guidelines

\begin{tabular}{|c|c|c|}
\hline Guidelines & Recommended INR range & Statements within the guidelines \\
\hline 2013 Japanese Circulation Society ${ }^{13}$ & $\begin{array}{l}\text { INR } 2.0-3.0 \\
\text { INR } 1.6-2.6 \text { (in patients aged } \geq 70 \text { years) }\end{array}$ & $\begin{array}{l}\text { To obtain maximum benefit from } \\
\text { warfarin therapy, the TTR should be } \\
\text { kept above } 60 \%\end{array}$ \\
\hline $\begin{array}{l}2015 \text { The Indian consensus } \\
\text { guidance on stroke } \\
\text { prevention in atrial fibrillation }\end{array}$ & $\begin{array}{l}\text { INR } 2.5(2.0-3.0)<75 \text { years } \\
\text { INR } 2.0(1.6-2.5)>75 \text { years }\end{array}$ & \\
\hline 2016 Taiwan Heart Rhythm Society ${ }^{10}$ & INR 2.0-3.0 & $\begin{array}{l}\text { The optimal therapeutic range of INR } \\
\text { in the use of warfarin has not been } \\
\text { fully established in Asians, although } \\
\text { an INR } 2.0-3.0 \text { is recommended } \\
\text { as the optimal } \\
\text { therapeutic range, with attention on } \\
\text { the average TTR; ideally }>65 \%\end{array}$ \\
\hline $\begin{array}{l}2016 \text { Chinese Geriatric Society }{ }^{15} \\
2018 \text { China Society of } \\
\text { Pacing and Electrophysiology/ } \\
\text { Chinese Society of Arrhythmia }\end{array}$ & $\begin{array}{l}\text { INR } 1.6-2.5>75 \text { years } \\
\text { INR } 2.0-3.0\end{array}$ & TTR $>65 \%$ \\
\hline $\begin{array}{l}2018 \text { Korean Heart } \\
\text { Rhythm Society }\end{array}$ & $\begin{array}{l}\text { Among patients receiving vitamin } \mathrm{K} \\
\text { antagonist, maintenance of an INR in } \\
\text { the therapeutic range }(2.0-3.0) \text { is essential }\end{array}$ & $\begin{array}{l}\text { When patients are treated with a } \\
\text { vitamin } \mathrm{K} \text { antagonist, TTR should be } \\
\text { kept as high as possible } \\
\text { (ideally aiming for TTR }>65-70 \% \text { ) and } \\
\text { be closely monitored }\end{array}$ \\
\hline
\end{tabular}

Abbreviations: INR, international normalized ratio; TTR, time in therapeutic range.

standard for prophylaxis of thromboembolism in AF, including in East Asians, who were thought to derive less harm from lower INR targets. ${ }^{16}$ This study nicely provided some important data regarding the "optimal" INR range for Asian AF patients. However, the clinical outcomes were compared between patients with an INR range of 1.5 to 2.0 and 2.0 to 3.0, and therefore, whether a lower INR within the standard range (2.0-2.5), could offer a good balance between ischemic and bleeding events remains unknown although this would pose more challenges to get a high TTR in that narrow range.

In a recent paper by McDowell et al, data on warfarintreated patients ( $n=21,883)$ from three clinical trials (RE-LY, ARISTOTLE, and ENGAGE AF-TIMI 48) were pooled. ${ }^{17}$ The event rates of ischemic stroke, ICH and all-cause mortality of patients in different INR strata are shown in - Fig. 1. An INR range between 2.0 and 2.5 appeared to offer a good balance

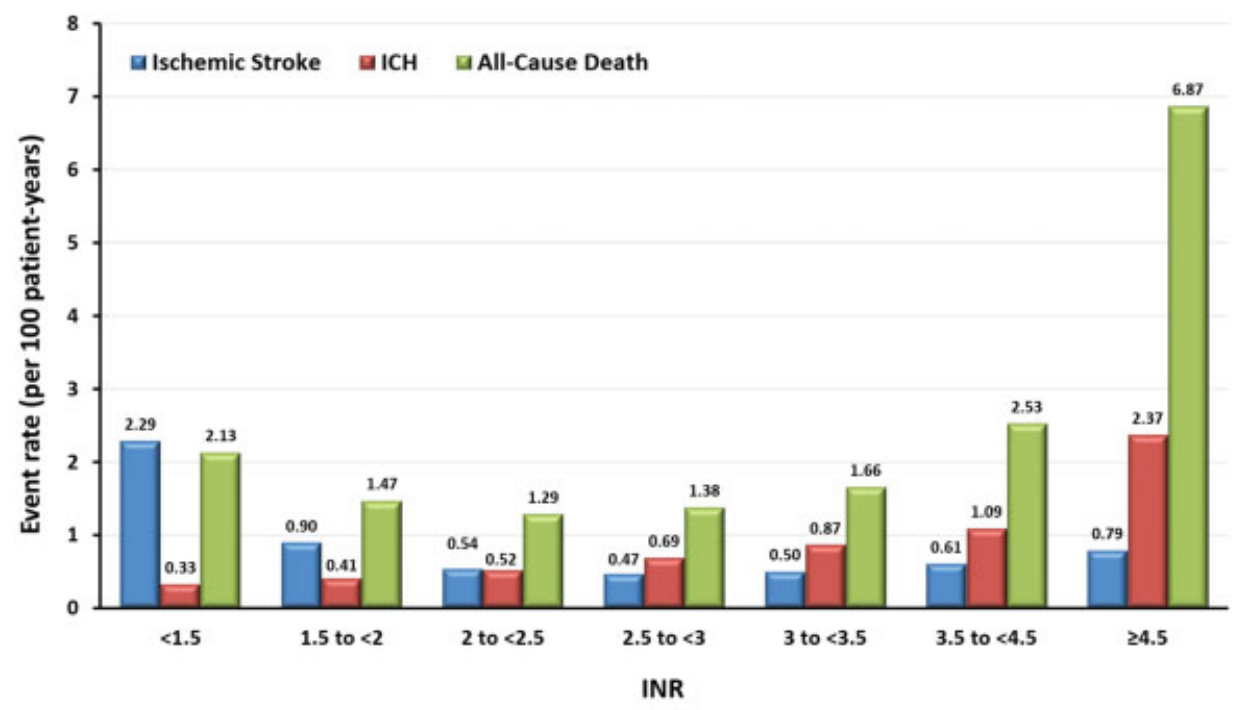

Fig. 1 Estimated risks of ischemic stroke, ICH and mortality among AF patients receiving warfarin in different INR ranges. An INR range between 2.0 and 2.5 appeared to offer a good balance between ischemic stroke and ICH, which was also associated with the lowest rate of all-cause death. ${ }^{*}$ The data used in the figure were from the paper by McDowell et al published in Pharmacotherapy $2018 .{ }^{17} \mathrm{AF}$, atrial fibrillation; ICH, intracranial hemorrhage; INR, international normalized ratio. 
between ischemic stroke and $\mathrm{ICH}$, which was also associated with the lowest rate of all-cause death. Although the annual stroke rate slightly increased from $0.47 \%$ for an INR 2.5 to 3.0 to $0.54 \%$ for an INR 2.0 to 2.5 , the risk of ICH decreased from 0.69 to $0.52 \% /$ year which was in favor of an INR range of 2.0 to 2.5 , considering the overall net clinical benefits. Even data specific for Asian AF patients were not reported, this largescale pooled analysis of high-quality data from clinical trials might imply that an INR range of 2.0 to 2.5 may be more appropriate than 2.5 to 3.0 for Asian patients who were at a high risk of ICH.

Overall, this study by Pandey et al nicely provides some unique data, but more high-quality studies, especially the prospective and randomized ones, are necessary to properly answer the optimal INR range for Asian AF patients. For now, we strongly recommend evidence-based management, with the strongest data currently for INR 2.0 to 3.0 and TTR ideally $>65 \%$ (or even $70 \%$ ). Evidence-based management should drive our clinical practice, not eminence or VIP-based opinion.

Funding

This work was supported in part by grants from the Ministry of Science and Technology (MOST 107-2314B-075-062-MY3), Taipei Veterans General Hospital (V108B-015, V108B-027, V108C-090), Research Foundation of Cardiovascular Medicine and Szu-Yuan Research Foundation of Internal Medicine, Taipei, Taiwan.

\section{Conflict of Interest}

None declared.

\section{References}

1 Chao TF, Liu CJ, Tuan TC, et al. Lifetime risks, projected numbers, and adverse outcomes in asian patients with atrial fibrillation: a report from the taiwan nationwide af cohort study. Chest 2018; 153(02):453-466

2 Bai Y, Wang YL, Shantsila A, Lip GYH. The global burden of atrial fibrillation and stroke: a systematic review of the clinical epidemiology of atrial fibrillation in Asia. Chest 2017;152(04):810-820

3 Lip GYH, Banerjee A, Boriani G, et al. Antithrombotic therapy for atrial fibrillation: CHEST guideline and expert panel report. Chest 2018;154(05):1121-1201

4 Lip G, Freedman B, De Caterina R, Potpara TS. Stroke prevention in atrial fibrillation: Past, present and future. Comparing the guide- lines and practical decision-making. Thromb Haemost 2017;117 (07):1230-1239

5 Chao TF, Chiang CE, Lin YJ, et al. Evolving changes of the use of oral anticoagulants and outcomes in patients with newly diagnosed atrial fibrillation in taiwan. Circulation 2018;138(14): $1485-1487$

6 Chao TF, Chen SA, Ruff CT, et al. Clinical outcomes, edoxaban concentration, and anti-factor Xa activity of Asian patients with atrial fibrillation compared with non-Asians in the ENGAGE AFTIMI 48 trial. Eur Heart J 2019;40(19):1518-1527

7 Kang J, Park KW, Ki YJ, et al. Development and validation of an ischemic and bleeding risk evaluation tool in east asian patients receiving percutaneous coronary intervention. Thromb Haemost 2019;119(07):1182-1193

8 Yoon M, Yang PS, Jang E, et al. Dynamic changes of CHA2DS2-VASc score and the risk of ischaemic stroke in asian patients with atrial fibrillation: a nationwide cohort study. Thromb Haemost 2018; 118(07):1296-1304

9 Lee LH, Gallus A, Jindal R, Wang C, Wu CC. Incidence of venous thromboembolism in asian populations: a systematic review. Thromb Haemost 2017;117(12):2243-2260

10 Chiang CE, Wu TJ, Ueng KC, et al. 2016 Guidelines of the Taiwan Heart Rhythm Society and the Taiwan Society of Cardiology for the management of atrial fibrillation. J Formos Med Assoc 2016; 115(11):893-952

11 Joung B, Lee JM, Lee KH, et al; KHRS Atrial Fibrillation Guideline Working Group. 2018 Korean guideline of atrial fibrillation management. Korean Circ J 2018;48(12):1033-1080

12 China Society of Pacing and Electrophysiology; Chinese Society of Arrhythmia. Current knowledge and management recommendations of atrial fibrillation:2018. Chinese Journal of Cardiac Pacing and Electrophysiology 2018;32:315-368

13 Group JCSJW; JCS Joint Working Group. Guidelines for pharmacotherapy of atrial fibrillation (JCS 2013). Circ J 2014;78(08): 1997-2021

14 Dalal J, Bhave A, Oomman A, et al; SPAF Academy India experts. The Indian consensus guidance on stroke prevention in atrial fibrillation: an emphasis on practical use of nonvitamin $\mathrm{K}$ oral anticoagulants. Indian Heart J 2015;67(Suppl 2):S13-S34

15 Chinese Geriatric Society. Expert consensus on the management of atrial fibrillation in elderly population. Chinese J Geriatric 2016;35:14-27

16 Pandey AK, Xu K, Zhang L, et al. Lower versus standard INR targets in atrial fibrillation: a systematic review and meta-analysis of randomized controlled trials. Thromb Haemost 2020;120(03): 484-494

17 McDowell TY, Lawrence J, Florian J, Southworth MR, Grant S, Stockbridge N. Relationship between international normalized ratio and outcomes in modern trials with warfarin controls. Pharmacotherapy 2018;38(09):899-906 